DOI: $10.14451 / 1.200 .115$

\title{
ОСНОВЫ КОМПЛЕКСНОГО ПОДХОДА К АНАЛИЗУ И ОЦЕНКЕ ДЕЯТЕЛЬНОСТИ ПРЕДПРИЯТИЯ АГРОПРОМЫШЛЕННОГО КОМПЛЕКСА
}

\section{(c) 2021 Суменков Сергей Михайлович}

кандидат экономических наук, доцент кафедры предпринимательского права Уральский государственный юридический университет, Россия, Екатеринбург

E-mail: ssm0001@yandex.ru

\section{(c) 2021 Васильева Марина Владимировна}

кандидат экономических наук, доцент кафедры предпринимательского права Уральский государственный юридический университет, Россия, Екатеринбург

E-mail: klokova.m.09@mail.ru

\section{(c) 2021 Никулина Татьяна Валерьевна}

кандидат экономических наук, доцент кафедры математики и информационных технологий Уральский государственный аграрный университет, Россия, Екатеринбург

E-mail: t.v.nikulina@inbox.ru

В статье рассмотрены методические основы комплексного подхода к анализу и оценке деятельности предприятия АПК. Предлагаемый подход предусматривает, что для оценки экономического состояния предприятия агропромышленного комплекса, достигнутого в результате реализации конкретного набора управленческих решений, целесообразно пользоваться как основными, так и относительными факторами.

Ключевые слова: Предприятие агропромышленного комплекса, факторный анализ, балансовый метод, управленческие решения, анализ ликвидности, кредитоспособность, финансовое планирование, экономические показатели.

В процессе формирования оптимальных объемно-календарных планов функционирования предприятия агропромышленного комплекса (далее АПК) возникает проблема сравнения и оценки этих планов в ограниченный промежуток времени, т.е. в режиме диалога между лицом принимающим решение и электронновычислительным устройством (компьютер). Ряд авторов в своих работах предлагают решать данную проблему в рамках решения задач многокритериальной оптимизации. На наш взгляд, подход многокритериальной оптимизации не полно учитывает взаимосвязи между факторами, влияющими на экономическую деятельность предприятия агропромышленного комплекса, поэтому существующая проблема не может быть полностью разрешена предлагаемыми и существующими способами. Научная новизна также проявляется в том, в статье предлагается решение задачи выбора оптимальной стратегии планирования работы предприятия агропромышленного комплекса по производству и реализации молочной продукции. Данная модель выбора позволяет сформировать планы экономической деятельности предприятия, сделать верный анализ его деятельности.

Для решения указанной проблемы необходимо, чтобы предпринимаемый анализ (сравнение и оценка) учитывал весьма широкий спектр технико-экономических показателей, достаточно полно характеризующих экономическую деятельность предприятия АПК. С целью формирования такой системы показателей, которые, с одной стороны, могли бы быть рассчитаны на основе принимаемых плановых решений, с другой стороны, в полной мере характеризовали бы все основные стороны экономической деятельности предприятия агропромышленного комплекса, необходимо проанализировать существующие методы экономического анализа, из которых выделим два основных:

1. Балансовый анализ, который непосредственно связан с обработкой информации, содержащейся в бухгалтерском балансе, и являющийся наиболее полным.

2. Факторный анализ зависимостей между исходными и результирующими экономическими показателями. 
Согласно балансовому методу оценка и анализ финансового состояния предприятия АПК производятся на основе, в первую очередь, бухгалтерской и статистической документации, которые базируются на официальных материалах и опыте зарубежных разработок.

Основными этапами анализа являются:

1) анализ доходности (рентабельности);

2) анализ финансовой устойчивости;

3) анализ кредитоспособности;

4) анализ использования капитала;

5) анализ уровня самофинансирования;

6) анализ валютной самоокупаемости.

Основными источниками информации для анализа финансового состояния предприятия АПК служат бухгалтерский баланс и приложения к нему, статистическая и оперативная отчетность.

Анализ доходности производится в сравнении с планом или с соответствующими показателями предшествующих периодов. В условиях наличия инфляционных процессов, волатильности курса национальной валюты, отсутствия механизма хеджирования мировых цен для внутреннего рынка, необходимо обеспечить сопоставимость показателей различных периодов путем введения соответствующих коэффициентов дисконтирования.

Подробный анализ финансового состояния предприятия АПК производится с помощью следующих основных приемов: сравнение, сводка и группировка, цепные подстановки, прием разниц. Иногда можно использовать методы оптимизации и регрессионного анализа.

Прием анализа заключается в сопоставлении финансовых показателей отчетного периода как с их плановыми (прогнозными) значениями, так и с аналогичными показателями предшествующих периодов.

Прием сводки и группировки заключается в объединении информационных материалов в аналитические таблицы, что дает возможность сделать необходимые сопоставления и выводы. Для выявления в процессе анализа взаимосвязи различных экономических показателей, определения наиболее информативных факторов, для выявления тенденций в развитии финансовых процессов используются эконометрические методы.

Прием цепных подстановок применяется для расчетов величины влияния отдельных факторов в общем комплексе их воздействия на уровни совокупного финансового показателя. Этот прием (при наличии достаточно большого числа наблюдений) сочетается с методами оценки информативности факторов в математической статистике.

Прием разниц заключается в том, что с его помощью определяют коэффициенты, характеризующие динамику экономического субъекта, что позволяет осуществлять сравнительный анализ его функционирования.

Доходность хозяйствующего субъекта характеризуется рядом абсолютных и относительных показателей, основными из которых среди абсолютных является прибыль, а среди относительных - рентабельность.

В процессе анализа, опираясь на имеющийся опыт, можно показать, что наиболее существенными факторами, влияющими на величину прибыли, являются: объем реализации продукции, уровень себестоимости, объем налоговых выплат.

Анализ сравнения плановых показателей с фактически достигнутыми позволяет ответить на ряд вопросов, в том числе, в случае расхождения показателей, выявить причины таких расхождений.

Так, например, на уровень рентабельности достаточно существенно влияет уровень себестоимости продукции. В свою очередь, на величину себестоимости влияют различные факторы, которые можно свести в следующие две группы:

- первая группа - внешние факторы, отражающие общий уровень развития экономики страны и не зависящие от деятельности хозяйствующего субъекта. Влияние этой группы факторов проявляется в уровне цен на энергоносители и сырье, тарифе на транспорт и воду, ставках арендной платы, отчислениях в фонды (пенсионный, медицинского и социального страхования), нормах амортизационных отчислений, видах конкурентной борьбы и др.

- вторая группа - внутренние факторы, непосредственно связанные с результатами деятельности хозяйствующего субъекта, с предпринимательской активностью. К этим факторам относятся, в первую очередь, производительность труда, цены реализации, использование основных фондов и оборотных средств и др.

После общего анализа хозяйственной деятельности предприятия агропромышленного комплекса необходимо проанализировать отдельные разделы более конкретно. 
Поскольку финансово устойчивым является такой хозяйствующий субъект, который за счет собственных средств покрывает средства, вложенные в активы (основные фонды, нематериальные активы, оборотные средства), не допускает неоправданной дебиторской и кредиторской задолженности и расплачивается в срок по своим обязательствам, то основой финансовой устойчивости, в первую очередь, является рациональная организация и использование оборотных средств. Поэтому, для снабженческосбытовых предприятий, в процессе анализа финансового состояния вопросам рационального использования оборотных средств должно быть уделено особое внимание. Анализ финансовой устойчивости включает следующие основные разделы:

- анализ состава и размещения активов хозяйствующего субъекта;

- анализ динамики и структуры источников финансовых ресурсов;

- анализ наличия собственных оборотных средств;

- анализ кредиторской задолженности;

- анализ дебиторской задолженности;

- анализ платежеспособности.

Под кредитоспособностью хозяйствующего субъекта обычно понимают качество использования кредита и его возврата в срок. Анализ условий кредитования предполагает изучение широкого круга вопросов, обеспечивающих ликвидность хозяйствующего субъекта. Ликвидность определяется соотношением величины задолженности и наличия средств, которые могут быть использованы для погашения долгов, к которым относятся: наличные средства и запасы нереализованной продукции; депозиты; ценные бумаги; реализуемые элементы оборотных средств и др.

Анализ ликвидности заключается в сравнении средств по активам, сгруппированным по степени их ликвидности и расположенным в порядке убывания ликвидности, с обязательствами по пассиву, объединением по срокам их погашения и в порядке возрастания сроков.

Основным показателем является оценка эффективности вложения капитала, под которой будем понимать его рентабельность. Уровень рентабельности капитала измеряется процентным отношением прибыли к величине капитала.

Другим важным показателем является уровень самофинансирования, который оценивает степень финансирования хозяйственной деятельности за счет собственных средств: амортизационных отчислений и прибыли. Коэффициент самофинансирования есть отношение величин собственных средств, к объему привлекаемых со стороны средств.

Данный балансовый метод позволяет осуществить комплексный анализ техникоэкономических данных, характеризующих финансовую деятельность предприятия, и выявить наиболее информативные разделы этой информации применительно к конкретно складывающейся на предприятии экономической ситуации.

Вместе с тем, необходимо отметить, что данный метод является достаточно полным и, следовательно, громоздким, требующим подготовки и сбора обширной исходной информации с использованием бухгалтерской отчетности, поэтому он, скорее, может использоваться для анализа выполнения плановых заданий, чем для сравнения и оценки различных вариантов плановых решений, для обоснования оптимальности принимаемых решений.

Факторный анализ осуществляет статистическое обоснование и последующий математический анализ зависимостей между факторными и результирующими экономическими показателями с целью структурирования и концентрации экономической информации для принятия управленческих решений.

Все множество факторов, участвующих в описании экономической деятельности предприятия, можно разбить на следующие три группы [4]:

1) факторы, характеризующие результаты хозяйственной деятельности предприятия;

2) факторы, характеризующие затраты, необходимые для достижения поставленных перед предприятием целей;

3) факторы, характеризующие объемы вовлекаемых в процесс производства ресурсов.

Для различных по своей сути предприятий АПК совокупности этих факторов могут быть разными в зависимости от специфики их хозяйственной деятельности. Однако есть определенные наборы факторов, которые необходимо обязательно использовать при анализе экономической деятельности предприятия агропромышленного комплекса.

К первой группе факторов, оценивающих результаты хозяйственной деятельности предпри- 
ятия АПК, необходимо отнести в первую очередь величину прибыли, которая формируется как часть валового дохода, остающаяся после вычета затрат на производственную деятельность, снабжение, сбыт, управление, выплаты по кредитам и уплату налогов. Этот показатель следует рассматривать как основной конечный результат хозяйственной деятельности предприятия агропромышленного комплекса.

Для комплексного анализа и ответа на ряд сформулированных выше проблем необходим также показатель, характеризующий общий объем выпуска продукции,- каковым является объем сельскохозяйственной продукции, иногда вместо этого показателя используется объем ее реализации.

В качестве характеристики деятельности предприятия АПК можно использовать величину полной себестоимости выпускаемой продукции.

Затраты, понесенные в процессе реализации управленческих решений, в силу функциональных различий их роли в хозяйственной деятельности предприятия АПК, объективно подразделяются на материальные, амортизацию, основные фонды и заработную плату.

Кроме этого, необходимо учитывать в общем случае поведение показателей, характеризующих величину вовлекаемых в хозяйственную деятельность предприятия АПК ресурсов, основные из них: объемы оборотных средств, основные производственные фонды, объемы кредитов и численность работающего персонала.

Рассмотрим возможную задачу, которую необходимо решать при формировании плана экономической деятельности предприятия агропромышленного комплекса, занимающегося производством молочной продукции - задачу выбора оптимальной стратегии планирования работы. Указанная задача является составной частью всего финансового планирования, поэтому предположим, что ряд параметров уже определены - установлены закупочные цены и цены реализации молочной продукции, а также известны существующие емкости предназначенные для молока, задан период планирования $\mathrm{t}(1, \ldots, \mathrm{T})$.

Цель решения данной задачи состоит в нахождении максимума суммарной величины приведенной прибыли от приобретения, переработки и реализации молочной продукции.
Введем следующие обозначения:

$\mathrm{ct}^{\mathrm{t}}$ - закупочная цена единицы молока в период $\mathrm{t}$

$\mathrm{p}^{\mathrm{t}}$ - цена реализации единицы молока в период $\mathrm{t}$

В - максимальная вместимость емкостей предприятия

$\mathrm{R}^{\mathrm{t}}$ - спрос на молоко в $\mathrm{t}-\mathrm{m}$ периоде

$\mathrm{x}^{\mathrm{t}}$ - количество закупаемого молока в $\mathrm{t}$-м периоде

$\mathrm{y}^{\mathrm{t}}$ - количество продаваемого молока в $\mathrm{t}-\mathrm{m}$ периоде.

В целях упрощения расчетов и в связи с краткосрочностью сделок будем считать, что показатели $\mathrm{c}^{\mathrm{t}}$ и $\mathrm{p}^{\mathrm{t}}$ уже индексированы на темпы инфляции.

Соответственно условие задачи сформулировано так, найти:

$\max \sum\left(\mathrm{p}^{\mathrm{t}} \mathrm{y}^{\mathrm{t}}-\mathrm{c}^{\mathrm{t}} \mathrm{x}^{\mathrm{t}}\right)$

$$
1, \mathrm{~T}
$$

при имеющихся ограничениях:

Количество имеющегося в наличии молока в конце t-го периода времени не может превышать вместимость имеющихся емкостей предприятия

$$
\mathrm{x}^{\mathrm{t}}-\mathrm{y}^{\mathrm{t}} \leqslant \mathrm{B}
$$

Количество продаваемого молока в t-м периоде не может превышать спроса в том же периоде времени

$$
\mathrm{y}^{\mathrm{t}} \leqslant \mathrm{R}^{\mathrm{t}}
$$

Рассмотрим практическую задачу, если период планирования равен 1. В данном случае задача выбора оптимальной стратегии, основанной на комплексном анализе деятельности предприятия молочного сектора агропромышленного комплекса, будет выглядеть следующим образом, найти:

$\max \left(\mathrm{p}^{1} \mathrm{y}^{1}-\mathrm{c}^{1} \mathrm{x}^{1}\right)$,

при условии, что

$\mathrm{x}^{1}-\mathrm{y}^{1} \leqslant \mathrm{~B}$

$x^{1} \geqslant 0$

$\mathrm{R}^{1} \geqslant \mathrm{y}^{1} \geqslant 0$

Основываясь на том, что $\mathrm{p}^{1}>\mathrm{c}^{1}$, приходим к выводу, что оптимальное значение функции (задачи стоящей перед предприятием АПК производителем молока) выглядит следующим образом:

$\max \left(\mathrm{p}^{1} \mathrm{y}^{1}-\mathrm{c}^{1} \mathrm{x}^{1}\right)=\mathrm{R}^{1}\left(\mathrm{p}^{1}-\mathrm{c}^{1}\right)+\mathrm{c}^{1}$

Соответственно, все имеющееся молоко в течении временного периода равного 1 будет реализовано и по окончании данного временного 
периода необходимо произвести его закуп.

Аналогично решаются задачи и для других временных периодов.

Следует отметить, что при выборе основных показателей, учитываемых при анализе экономической деятельности предприятия агропромышленного комплекса, необходимо учитывать специфику функционирования предприятия, в частности для перерабатывающих предприятий важно выделить ряд дополнительных факторов:

1) затраты на приобретение кормов и удобрений;

2) затраты на содержание скота;

3) объемы непрофильных работ и т.д.
Рассмотрев общую ситуацию, можно сформулировать следующее - для оценки экономического состояния предприятия агропромышленного комплекса, достигнутого в результате реализации конкретного набора управленческих решений, целесообразно пользоваться следующими основными свободными показателями: прибыль, товарная продукция, себестоимость, материальные затраты, амортизация основных фондов, заработная плата, оборотные средства, основные производственные фонды, кредиты (инвестиции), численность работающих.

\section{Библиографический список}

1. А.Д. Шеремет. Теория экономического анализа: Учебник / - 3-е изд., доп.- М.: ИНФРА-М, 2011. - 352 с.

2. Балабанов И. Т. Основы финансового менеджмента. М.: Финансы и статистика, 1995, 384c.

3. Васильева М.В., Тарабаева Н.М. Конкуренция в условиях цифровизации экономики // Экономика и предпринимательство, № 6, 2019. p.1303-1305

4. Джамалутдинова 3. М. Методические подходы к мониторингу предприятий АПК. // Региональные проблемы преобразования экономики № 12, 2015, с..31-37.

5. Паршуков Д.В., Ходос Д.В. К вопросу о многокритериальной оценке экономической эффективности предпринимательской деятельности субъекта в АПК // Бюллетень КрасГАУ, № 3, 2015, с. 169-172.

6. Суменков М.С., Суменков С. М., Новикова Н.Ю. Методология прогнозирования технико-экономических параметров предприятия в условиях неопределенности //Экономические науки, № 5, 2020, с 114-199.

7. C. Dougherty Introduction to Econometrics, Fourth Edition, Oxford University Press, 2011, 573p.

8. M. Eddowes, R. Stansfield Decision Making Techniques (ACCA). Longman Group UK Ltd, 1991, 176p. 